Dokuz Eylül Üniversitesi-Mühendislik Fakültesi Fen ve Mühendislik Dergisi Cilt 20, Sayı 60, Eylül, 2018
Dokuz Eylul University-Faculty of Engineering Journal of Science and Engineering Volume 20, Issue 60, September, 2018

DOI: $10.21205 /$ deufmd. 2018206072

\title{
Yağış Sularının Ağır Metal İçeriğinin Uzaklaştırılmasında Doğal Zeolitlerin Etkinliğinin Araştırılması
}

\author{
Fatih TURAN ${ }^{*}$, Sezai ȘEN ${ }^{2}$ \\ Dokuz Eylül Üniversitesi, Mühendislik Fakültesi, Maden Mühendisliği Bölümü, 35160, İzmir. \\ 1(ORCID: 0000-0002-9969-0405) \\ 2(ORCID: 0000-0002-0855-4388)
}

(Alınış / Received: 20.03.2018, Kabul / Accepted: 18.06.2018, Online Yayınlanma / Published Online: 15.09.2018)

Anahtar Kelimeler Özet: Günümüzde, motorlu araçlar, endüstriyel işletmeler ve yaşam Zeolit,

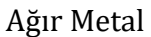
Adsorpsiyonu, $\mathrm{Zn}, \mathrm{Cr}, \mathrm{Ni}, \mathrm{Cd}$ alanlarında üretilen atıklardan kaynaklanan ağır metallerin, yağmur sularına karışarak çevre kirliliğine sebep olması, insanlığın karşılaștığı en büyük problemlerden biri haline gelmiștir. Bu çalışmada, şimdiye kadar tespit edilmiş en yüksek ağır metal içeriğine sahip yağmur sularını temsil edecek şekilde hazırlanmış Zn, $\mathrm{Ni}, \mathrm{Cr}$ ve $\mathrm{Cd}$ ağır metallerini içeren çözeltiler kullanılmıș ve bu ağır metallerin zeolit üzerine adsorpsiyonu araştırılmıştır. İnce taneli zeolit örneklerinin görece kısa adsorpsiyon sürelerinde iri taneli örneklere göre daha başarılı olduğu ancak sürenin uzaması durumunda (120 saat) tüm örneklerin adsorpsiyon verimlerinin oldukça yakın değerlere ulaștığı gözlenmiștir. Araștırma sonucunda, kullanılan Gördes yöresi doğal zeolitinin, söz konusu ağır metallerin adsorpsiyonunda oldukça başarılı olduğu sonucuna ulaşılmıştır. Çalışılan başlangıç konsantrasyonları için, trivalent yüklü iyonların $\left(\mathrm{Cr}^{3+}\right)$ katyonların adsorpsiyon verimlerinin bivalent yüklü $\left(\mathrm{Zn}^{2+}, \mathrm{Ni}^{2+}, \mathrm{Cd}^{2+}\right)$ katyonların adsorpsiyon verimlerine nazaran daha düşük olduğu gözlenmiştir.

\section{Investigation Of The Effectiveness Of Natural Zeolites In The Removal Of Heavy Metal Contents From Stormwater}

Keywords: Abstract: Today, heavy metals originating from motor vehicles, Zeolite; heavy metal industrial enterprises and waste generated in living areas cause adsorption, $\mathrm{Zn}, \mathrm{Cr}$, environmental pollution by mixing urban stormwater which have $\mathrm{Ni}, \mathrm{Cd}$. become one of the biggest problems humanity faces. In this study, solutions containing heavy metals such as $\mathrm{Zn}, \mathrm{Ni}, \mathrm{Cr}$ and $\mathrm{Cd}$ were prepared to simulate the urban stormwater with the highest heavy metal concentrations determined up to now and adsorption of these heavy metals on zeolite has been investigated. It was found that the zeolite samples in fine size fractions were more successful than the 
coarse samples in relatively shorter adsorption periods but the adsorption efficiency of all the samples in different particle size fractions reached to very close values (120 hours). It is concluded that Gördes natural zeolite used is very successful in the adsorption of heavy metals in question. Adsorption efficiencies of trivalent charged cations $\left(\mathrm{Cr}^{3+}\right)$ were observed to be lower than adsorption efficiencies of bivalent charged cations $\left(\mathrm{Zn}^{2+}, \mathrm{Ni}^{2+}, \mathrm{Cd}^{2+}\right)$ for working initial concentrations.

*Sorumlu yazar: fatih.turan@deu.edu.tr

\section{Giriș}

Günümüzde, endüstriyel işletmeler ve yaşam alanlarında üretilen atıklardan kaynaklanan ağır metaller, yağmur sularına karıșarak çevre kirliliğine sebep olarak, toplum sağlığını tehdit eden büyük problemlerden biri haline gelmiştir. Bir çok araştırmacl, aşağıda ayrıntısı verildiği üzere, araç lastiklerinden, araçların eksozlarından, asfaltlardan ve tozlardan kaynaklanan ağır metallerin çevreye zarar verdiğini belirtmișler ve son dönemlerde bu konuda birçok bilimsel çalışmalar yapmıșlardır.

Kentsel yağmur sularından farklı filtre malzemeleri kullanarak metallerin uzaklaştırılmasını araștıran Krishna ve ark., 2014 yllında zemine döşenen geçirgen ve reaktif filtre sistemlerinin, kontamine olmuş kentsel yağmur sularının iyileştirmesine yardımcı olabileceğini düșünmüșlerdir. Öncelikle kalsit, zeolit, kum, ve demir talașı gibi filtre malzemelerini seçmişler ve içinde farklı konsantrasyonda $\mathrm{Cd}, \mathrm{Cu}, \mathrm{Pb}, \mathrm{Ni}, \mathrm{Cr}$ ve $\mathrm{Zn}$ içeren altı farklı ağır metal çözeltisi hazırlayarak adsorblanan ağır metallerin, $\mathrm{pH}$, yükseltgenme ve indirgenme potansiyelleri, elektrik iletkenliklerini tespit etmişlerdir. Çalışmalarında; ağır metal adsorpsiyonun ve metallerin uzaklaștırılma miktarının, metalin türüne, konsantrasyonuna ve filtre malzemesine bağlı olduğunu tespit etmișlerdir. Langmuir veya Freundlich izotermlerinin, metal adsorpsiyon davranıșını en iyi șekilde açıkladığını, hazırlanan çözeltilerden metallerin ayrılması oranlarının ise kalsit, zeolit ve demir talaşının $\mathrm{Cd}, \mathrm{Cu}, \mathrm{Pb}$ ve $\mathrm{Zn}$ için \% 95100 aralığında, Ni oranının zeolit ile \%90 oranında, $\mathrm{Cr}$ oranının ise demir talaşı ile \% 100 oranında olduğunu belirtmișlerdir. Sonuçta, tek başına hiçbir filtre malzemesinin tüm ağır metallerin gideriminde başarılı olmadığı, bu gibi arıtım ișlemlerinde, söz konusu filtre malzemelerinin karışımının kullanılması gerektiğine işaret etmişlerdir [1].

Katarzyna ve ark., 2014 yılında yol kenarı akışlarından geçirgen reaktif bariyer olarak zeolit kullanımıyla çözünmüș metallerin temizlenmesi konusunda bir çalışma yapmışlardır. Araştırmacılar; yol ağları ve petrol istasyonu, yol drenaj sistemleri gibi yol alt yapılarının çevre kirliliğinin anahtar kaynakları olduğunu ifade etmiş̧lerdir. $\mathrm{Bu}$ yüzden, yeraltı sularının kabul edilebilir kalitesini sağlamak için, uygun bir koruma sistemi gerektiğini belirtmișlerdir. Çalışmalarında PRB (Permeable reactive barrier) kullanmışlar ve yol akışlarının sulu çözeltilerinde zeolit kullanarak $\mathrm{Cu}$, $\mathrm{Zn}, \mathrm{Pb}, \mathrm{Ni}, \mathrm{Cd}$ gibi ağır metallerin uzaklaștırılması üzerinde durmuşlardır. Sonuç olarak, çözeltide rekabetçi katyonların oluşmasının kurşun ve bakır konsantrasyonlarını azalttığını belirtmișler ve sulu çözeltilerden ağır metal temizleme yüzdelerini $\mathrm{Cd}$ için $\% 54$, $\mathrm{Cu}$ için \% 31, Ni için \% 48, Zn için \% 92, ve $\mathrm{Pb}$ için \% 70 olarak tespit ederek, zeolitin metal katyonlarının yol akışlarından 
uzaklaştırılmasında umut vaat eden bir araç olabileceğini ifade etmişlerdir [2].

Fuhrman ve ark. 2007 yılında, yağmur suyundan As, Cd, Cr, Cu, Ni ve Zn 'nin aynı anda temizlenmesi ve 11 farklı sorbentin karşılaştırılması konusunda deneysel bir çalışma yapmışlardır. Yağmur sularından ağır metallerin temizlenmesi amacı ile alümina, aktive edilmiş bouxol kaplanmış kum (ABCS), ağaç kabuğu, bouxol kaplanmış kum (BCS), uçucu kül (FA), granül aktif karbon (GAC), granül ferrik hidroksit (GFH), demir oksit ile kaplanmış kum (IOCS), doğal zeolit (NZ), kum ve spinel $\left(\mathrm{MgAl}_{2} \mathrm{O}_{4}\right)$ 'in potansiyelini araştırmışlardır. Metal çeşitliliği ve saturasyonu verileri PHREEQ-C jeokimyasal modele uygulanmış ve böylece BCS, FA ve spinelin ağırlıklı olarak katyonik ve yüklü olmayan iyonların anyonik türlere kıyasla belirgin olarak daha yüksek afinitesi olduğunu belirtmişlerdir. Ayrıca, IOCS, NZ, ve kumun As ve Cr'a karşı yüksek afiniteye sahipken, alüminanın ise test edilen tüm ağır metallere eşit derecede yüksek afinite gösterdiğini ifade etmişlerdir [3].

Göbel ve ark., 2007 yılında kentsel alanlar için fırtına sonucu oluşan suyun akış konsantrasyonu matrisi üzerine derleme bir çalışmaya imza atmışlardır. Araştırmacılar, arazi geliştirmek ve kentleşme süreci sırasında eklenen altyapıların (yollar, kaldırımlar, ticari ve konut yapıları) ve havzalardan yağış toplamak, özellikle akarsular ve nehirler gibi mevcut yüzey suyu kanallarına iletmek üzere tasarlandıklarını ifade etmişlerdir. Yüzey sularının, sızıntı suyu ve yeraltı sularının kalitesinin, geçirimsiz yüzeylerde toplanan ve yağmur su akışı ile taşınan kirleticilerden etkilendiğini belirtmişlerdir. Kasırga sularında yer alan ağır metallerin, (özellikle $\mathrm{Pb}, \mathrm{Zn}, \mathrm{Cu}, \mathrm{Cd}$ gibi) poliaromatik hidrokarbonların, mineral yağlı hidrokarbonların, çözünmüş tuzların, suların kalitesinin bozulmasına katkıda bulunduklarının altını çizmişlerdir [4].

Erdem ve ark. 2004 yllında ağır metal katyonlarının doğal zeolitler tarafından uzaklaştırılması konulu çalışmalarında klinoptilolit türü zeolitlerin $\mathrm{Co}^{+2}, \mathrm{Cu}^{+2}$, $\mathrm{Zn}^{+2}$ ve $\mathrm{Mn}^{+2}$ 'ye karşı adsorpsiyon davranışlarını incelemişler ve saf metal arıtmayla atıksulara uygulanmasını değerlendirmişlerdir. Klinoptilolit metal katyonlarının adsorpsiyon oranlarının Langmuir, Freundlich ve Dubininkaganer-Radushkevich adsorpsiyon izoterm verileriyle eşleştiği ve her bir katyon değişimine eklendiğini saptamışlardır. İlgili eşitliklere göre seçicilik sırası $\mathrm{Co}^{+2}>\mathrm{Cu}^{+2}>\mathrm{Zn}^{+2}>\mathrm{Mn}^{+2}$ olarak oluştuğu ve bu sonuçların endüstriyel atıksulardan ağır metallerin giderilmesinde zeolitin yüksek potansiyel gösterdiğini belirtmişlerdir [5].

\section{Materyal ve Metot \\ 2.1. Materyal}

Çalışmada Gördes yöresi klinoptilolit türü doğal zeolit kullanılmıştır. Zeolit cevheri çeneli kırıcı kullanılarak -3,35 mm altına kapalı devre kırma uygulaması ile ufalanmıştır. Elde edilen malzemeden temsili olarak alınan analiz numuneleri, halkalı değirmen kullanılarak -106 mikron tane boyutu altına öğütülmüştür. Perkin Elmer Marka PINAAcle 500 model atomik absorbsiyon spektrofotometresi ile deneylerde kullanılan zeolit cevherinin kimyasal analizi yapılmış ve kimyasal kompozisyonu Tablo 1'de sunulmuştur. Malzemenin geri kalan kısmı deneylerde kullanılmak üzere elek kullanılarak, 3,35$2 \mathrm{~mm}, 2-1 \mathrm{~mm},-1 \mathrm{~mm}$ ve $-0,212 \mathrm{~mm}$ tane sınıflarına ayrılmıştır. 
Tablo 1. Zeolit Cevherinin Kimyasal Bileșimi

\begin{tabular}{cc}
\hline Parametre & $\%$ \\
\hline $\mathrm{SiO}_{2}$ & 69,30 \\
$\mathrm{Al}_{2} \mathrm{O}_{3}$ & 11,40 \\
$\mathrm{Fe}_{2} \mathrm{O}_{3}$ & 1,15 \\
$\mathrm{CaO}$ & 1,95 \\
$\mathrm{MgO}$ & 0,84 \\
$\mathrm{Na} 2$ & 0,38 \\
$\mathrm{~K}_{2} \mathrm{O}$ & 3,80 \\
$\mathrm{Cr}_{2} \mathrm{O}_{3}$ & $<0,01$ \\
$\mathrm{TiO}_{2}$ & 0,07 \\
$\mathrm{MnO}$ & 0,01 \\
$\mathrm{P}_{2} \mathrm{O}_{5}$ & 0,02 \\
$\mathrm{SrO}$ & 0,04 \\
$\mathrm{BaO}$ & 0,03 \\
Kizdirma Kaybl & 10,10 \\
\hline
\end{tabular}

\subsection{Metot}

Metal iyonlarının analizi için Perkin Elmer marka PinAAcle 500 model Atomik Absorpsiyon Spektrofotometresi (AAS) cihazı ve VARIAN Marka 700 model ICPOES cihazı kullanılmıștır. pH ölçümleri WTW marka pH 3110, pH metre ile yapılmıștır. Çözeltilerin hazırlanmasında Brand marka ayarlanabilir hacimli mikropipet $(0,5-5 \mathrm{~mL}, 100-1000 \mu \mathrm{L}$ ve 10 $100 \mu \mathrm{L})$ kullanılmıştır. Ultra saf su için, Mili-Q (Milipore) marka ultra saf su cihazı kullanılmıștır.

Ağır metal adsorpsiyonu testlerinde çalışılan $\mathrm{Cd}, \mathrm{Cr}$, Ni ve $\mathrm{Zn}$ için $1000 \mathrm{mg} / \mathrm{L}$ ana stok çözeltilerinden, $\mathrm{Cd}$ için 11,2 $\mathrm{mg} / \mathrm{L}, \mathrm{Cr}$ için $211 \mathrm{mg} / \mathrm{L}, \mathrm{Ni}$ için 155,6 $\mathrm{mg} / \mathrm{L}, \mathrm{Zn}$ için 573,3 mg/L derişimlerinde, dünyada yüzeysel yağmur sularında tespit edilmiş olan en yüksek ağır metal konsantrasyonlarını içeren çözeltiler hazırlanmıştır [4].

Çalıșmalarda Gördes yöresi 3,35-2 mm, 2$1 \mathrm{~mm},-1 \mathrm{~mm}$ ve $-0,212 \mathrm{~mm}$ boyutlarında olmak üzere 4 farklı tane sinıfında hazırlanmış zeolit cevheri kullanılmıștır. Bu tane sinıflarındaki her bir numuneden $100 \mathrm{~mL}$ hacimli polipropilen kapakl numune şişeleri içerisine \% 5 katı oranında zeolit ve stok çözeltisi içeren süspansiyonlar hazırlanmıştır. Hazırlanan örneklerin kapakları kapatılıp
30 saniye boyunca elle çalkalanıp dinlendirilmiștir. İlk numuneler 4 saat sonra alınmış, ardından 48. ve 120 . saatlerde numune alınmaya devam edilmiştir. Numune alma işlemleri için 5 $\mathrm{mL}$ hacimli otomatik pipet kullanılmış ve element konsantrasyonları ICP-OES kullanılarak belirlenmiștir.

\section{Bulgular}

Çalışmada Gördes kliniloptilolit türü zeolit cevheri, malzeme ve yöntem bölümünde açılklandığı şekilde $3,35-2$ $\mathrm{mm}, 2-1 \mathrm{~mm},-1 \mathrm{~mm}$ ve $-0,212 \mathrm{~mm}$ tane sınıflarında hazırlandıktan sonra adsorpsiyon testlerine tabi tutulmuștur. Zeolitlerin liç işlemleri sonucu 4 saat, 48 saat ve 120 saat süreler sonunda ICP-OES cihazında $\mathrm{Cd}, \mathrm{Cr}$, $\mathrm{Ni}$ ve $\mathrm{Zn}$ okumaları yapılmış ve zeolit üzerine ağır metal adsorpsiyonları, adsorpsiyon verimleri belirlenmiştir. $\mathrm{Cr}$ elementine ait adsorpsiyon ve adsorpsiyon verimi değerleri Şekil 1 ve Şekil 2'de gösterilmiștir.

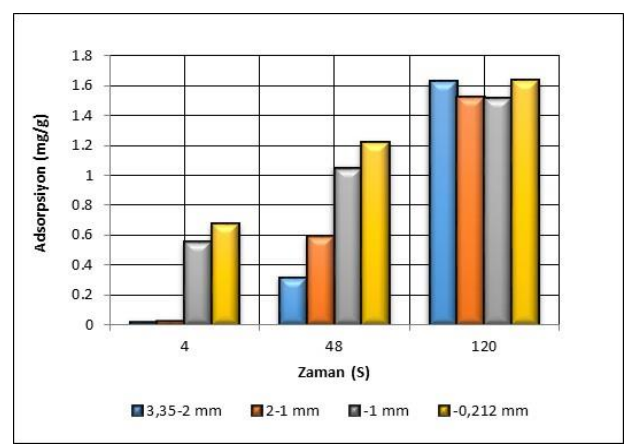

Şekil 1. Zamana bağlı olarak farklı tane sınıflarındaki zeolit üzerine $\mathrm{Cr}$ adsorpsiyonu konsantrasyon değerleri 


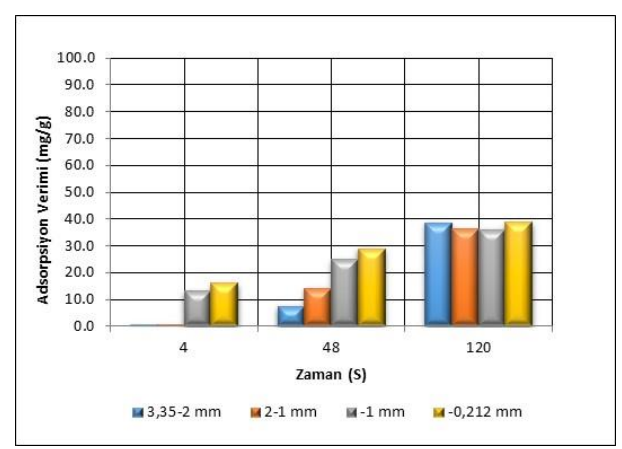

Şekil 2. Zamana bağlı olarak farklı tane sınıflarındaki zeolit üzerine $\mathrm{Cr}$ adsorpsiyonu verim değerleri

211 ppm Cr bașlangıç konsantrasyonuna sahip çözelti ile yapılan çalıșmalar sonucunda, en iri iki tane sinıfindaki zeolit örnekleri kullanıldığında zeolit üzerine Cr adsorpsiyonunun sinırlı olarak gerçekleștiği tespit edilmiştir. İlerleyen saatlerde bu tane siniflarına $\mathrm{Cr}$ adsorpsiyonu artış göstermekteyse de, ilk 48 saat içerisinde $-1 \mathrm{~mm}$ ve $-0,212 \mathrm{~mm}$ tane sinıflarındaki zeolit örneklerinin adsorpsiyon verimleri diğer tane sınıflarına göre daha yüksek değerlerdedir. 120 saatlik adsorpsiyon süresi sonucunda tüm tane sinıflarında adsorpsiyon verimlerinin birbirine oldukça yaklaştığı, tüm tane sınıflarında zeolit üzerine $\mathrm{Cr}$ adsorpsiyonunun 1,5-1,6 $\mathrm{mg} / \mathrm{g}$ civarında gerçekleştiği tespit edilmiștir. 3,35-2 mm, 2-1 mm, -1 mm ve $-0,212 \mathrm{~mm}$ tane sinıflarına göre adsorpsiyon verimleri sırasıyla, \% 38,6, \% $36,2, \quad \% 36,0$ ve $\% 38,8$ olarak hesaplanmıștır. Çözeltide $\mathrm{Cr}, \mathrm{Cr}+3$ katyonu olarak bulunmaktadır [2-12]. $\mathrm{Cr}^{+3}$ ün hidroliz reaksiyonları 1-4 eşitliklerinde verildiği şekilde gerçekleşmektedir.

$$
\begin{aligned}
& \mathrm{Cr}^{3+}+\mathrm{H}_{2} \mathrm{O} \leftrightarrow \mathrm{Cr}(\mathrm{OH})^{+2}+\mathrm{H}^{+} \\
& \mathrm{pK}_{1}=3,83 \\
& \mathrm{Cr}^{+3}+2 \mathrm{H}_{2} \mathrm{O} \leftrightarrow \mathrm{Cr}(\mathrm{OH})_{2}+2 \mathrm{H}^{+} \\
& \mathrm{pK}_{2}=10,06 \\
& \mathrm{Cr}^{+3}+3 \mathrm{H}_{2} \mathrm{O} \leftrightarrow \mathrm{Cr}(\mathrm{OH})_{3}^{0}+3 \mathrm{H}^{+} \\
& \mathrm{pK}_{3}=18,70
\end{aligned}
$$

$$
\begin{aligned}
& \mathrm{Cr}^{+3}+4 \mathrm{H}_{2} \mathrm{O} \leftrightarrow \mathrm{Cr}(\mathrm{OH})_{4}^{+5}+4 \mathrm{H}^{+} \\
& \mathrm{pK}_{4}=8,40
\end{aligned}
$$

Zn elementine ait adsorpsiyon ve adsorpsiyon verimi değerleri Şekil 3-4'de verilmiştir.

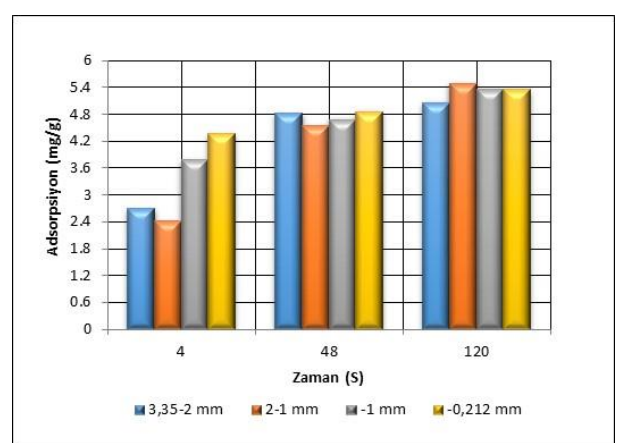

Şekil 3. Zamana bağlı olarak farklı tane sinıflarındaki zeolit üzerine $\mathrm{Zn}$ adsorpsiyonu konsantrasyon değerleri

Adsorpsiyon testleri, 573,3 ppm $\mathrm{Zn}^{2+}$ içeren çözelti ile yapılmış ve testlerinin sonunda $1 \mathrm{~g}$ zeolitin adsorbe ettiği $\mathrm{Zn}$ miktarı olarak değerlendirilmiştir. 3,35-2 $\mathrm{mm}$ ve $2-1 \mathrm{~mm}$ tane sinıfındaki zeolit örneklerinde adsorpsiyon miktarı 4 saat sonunda sirasiyla 2,67 ve $2,41 \mathrm{mg} / \mathrm{g}$ olduğu, buna karşılık olarak adsorpsiyon verimlerinin \% 23,44 ve 21,02 olarak gerçekleștiği saptanmıștır. Öte yandan, -1 ve $-0,212$ tane siniflarındaki zeolit örnekleri kullanıldığında aynı zaman dilimi sonucunda zeolitin $\mathrm{Zn}$ adsorpsiyon miktarlarının sırasıyla 3,78 ve $4,36 \mathrm{mg} / \mathrm{g}$ değerlerinde olduğu, adsorpsiyon verimlerinin ise \% 32,98 ve \% 38,04 olarak gerçekleştiği gözlenmiştir. 120 saat sonunda ise 3,35-2, 2-1, -1, ve -0,212 mm tane sinıflarındaki $\mathrm{Zn}$ adsorpsiyon miktarlarının sırasıyla 5,07, 5,49, 5,35 ve $5,35 \mathrm{mg} / \mathrm{g}$ olduğu, adsorpsiyon verimlerinin ise sirasiyla $\% 44,2, \% 47,8$, $\% 46,7$ ve $\% 46,6$ olarak gerçekleştiği tespit edilmiștir.

$\mathrm{Cr}^{+3}$ katyonunun zeolit tarafından adsorblanması dört kademede gerçekleşmektedir, dolayısı ile ortam $\mathrm{pH}^{\prime}$ 
ının etkisi, adsorblanma süresiyle direk ilgilidir. Ortamdaki yük dengesinin, diğer türler bakımından farklı olan trivalent $\mathrm{Cr}^{+3}$ katyonunun adsorblanma süresini uzattığı düşünülmektedir [6].

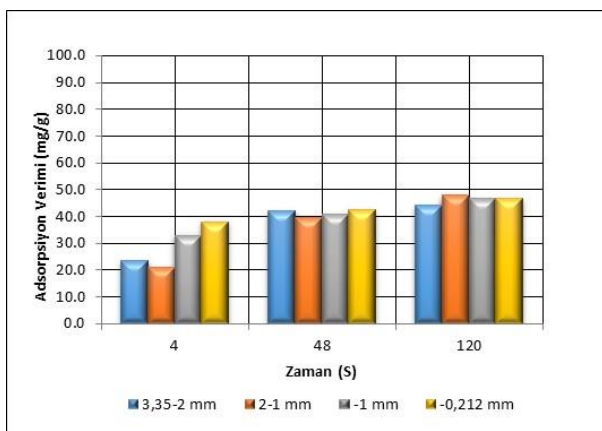

Şekil 4. Zamana bağlı olarak farklı tane sinıflarındaki zeolit üzerine Zn adsorpsiyonu verim değerleri

$\mathrm{Cr}^{+3}$ katyonunun adsorpsiyonunda olduğu gibi Zn adsorpsiyon verimleri ilk dört saat içerisinde ince tane sınıflarında daha yüksektir. Dolayısıyla, adsorbant yüzey alanının genişlemesi ile birlikte $\mathrm{Zn}$ katyonunun adsoprsiyon verimlerinin artmış olduğundan bahsetmek mümkündür. Ancak, $\mathrm{Cr}^{+3}$ katyonundan farklı olarak Zn katyonu zeolit üzerine aşağıda verilen şekilde (Eşitlik 5) kimyasal olarak adsorbe olmaktadır [7].

$$
\mathrm{Na}-\mathrm{Z}+\mathrm{ZnCl}_{2} \leftrightarrow \mathrm{Zn}-\mathrm{Z}+\mathrm{NaCl}
$$

Zn katyonunun çözelti içerisindeki farklı derişimlerine bağlı hidroliz reaksiyonları Eşitlik 6-9'da verilmiștir [8].

$$
\begin{aligned}
& \mathrm{Zn}^{2+}+\mathrm{H}_{2} \mathrm{O} \leftrightarrow \mathrm{Zn}(\mathrm{OH})^{+}+\mathrm{H}^{+} \\
& p K_{1}=8,96 \\
& \mathrm{Zn}^{2+}+2 \mathrm{H}_{2} \mathrm{O} \leftrightarrow \mathrm{Zn}(\mathrm{OH})_{2}+2 \mathrm{H}^{+} \\
& p K_{2}=7,94 \\
& \mathrm{Zn}^{2+}+3 \mathrm{H}_{2} \mathrm{O} \leftrightarrow \mathrm{Zn}(\mathrm{OH})_{3}{ }^{-}+3 H^{+} \\
& p K_{3}=11,50 \\
& \mathrm{Zn}^{2+}+4 \mathrm{H}_{2} \mathrm{O} \leftrightarrow \mathrm{Zn}(\mathrm{OH})_{4}{ }^{2-}+4 H^{+} \\
& p K_{4}=12,00
\end{aligned}
$$

$\mathrm{Ni}$ elementine ait adsorpsiyon ve adsorpsiyon verimi değerleri Şekil 5-6'da verilmiștir.

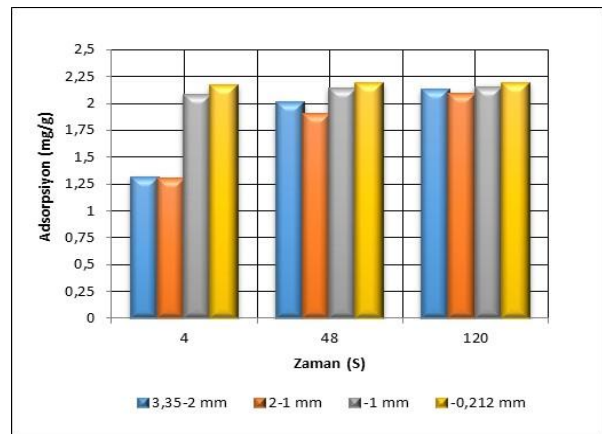

Şekil 5. Zamana bağlı olarak farklı tane sinıflarındaki zeolit üzerine $\mathrm{Ni}$ adsorpsiyonu konsantrasyon değerleri

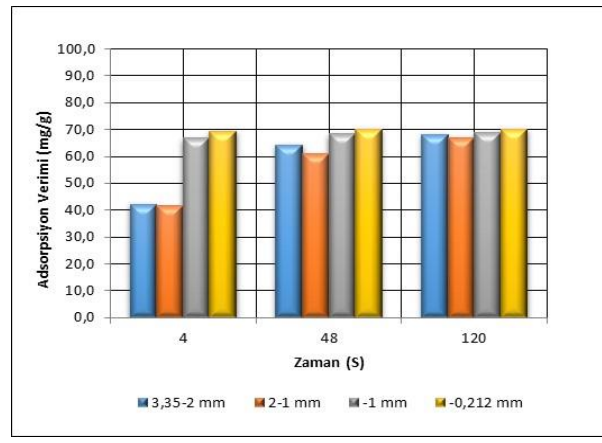

Şekil 6. Zamana bağlı olarak farklı tane sınıflarındaki zeolit üzerine $\mathrm{Ni}$ adsorpsiyonu verim değerleri

$\mathrm{Ni}$ iyonu adsorpsiyon testleri, başlangıç derişimi $155,6 \mathrm{ppm} \mathrm{Ni}^{2+}$ olan çözelti ile yapılmıştır.Testlerin sonunda, 1g zeolitin adsorbe ettiği $\mathrm{Ni}^{2+}$ miktarı, 3,35-2 mm ve 2-1 mm tane boyutlarında 4 saat sonunda sırasıyla 1,31 ve $1,29 \mathrm{mg} / \mathrm{g}$ olduğu, adsorpsiyon verimlerinin ise $\% 42,10$ ve 41,58 olarak gerçekleştiği görülmüştür. $1 \mathrm{~mm}$ ve $-0,212 \mathrm{~mm}$ tane sinıfında ise 4 saat sonundaki adsorpsiyon miktarları 2,08 ve $2,16 \mathrm{mg} / \mathrm{g}$ olduğu, adsorpsiyon verimlerinin ise $\% 66,71$ ve 69,41 olarak gerçekleștiği tespit edilmiștir. 120 saat sonunda ise adsorpsiyon miktarlarının tüm tane sinıflarında sirasyla 2,12, 2,08, 2,15 ve $2,18 \mathrm{mg} / \mathrm{g}$ olduğu, adsorpsiyon verimlerinin ise sırasıyla $\% 68,3, \% 67,0$, 
$\%$ 69,0 ve $\% 70,2$ olarak gerçekleştiği gözlenmiştir. $\mathrm{Ni}$ iyonu hidroliz reaksiyonları $\quad 10-13 \quad$ eşitliklerinde verilmiştir [9].

$$
\begin{aligned}
& \mathrm{Ni}^{2+}+\mathrm{H}_{2} \mathrm{O} \leftrightarrow \mathrm{Ni}(\mathrm{OH})+\mathrm{H}^{+} \\
& \mathrm{pK}_{1}=4,1 \\
& \mathrm{Ni}^{2+}+2 \mathrm{H}_{2} \mathrm{O} \leftrightarrow \mathrm{Ni}(\mathrm{OH})_{2}+2 \mathrm{H}^{+} \\
& \mathrm{pK}_{2}=8,5 \\
& \mathrm{Ni}^{2+}+3 \mathrm{H}_{2} \mathrm{O} \leftrightarrow \mathrm{Ni}(\mathrm{OH})_{3}{ }^{-}+3 \mathrm{H}^{+} \\
& \mathrm{pK}_{3}=11,50 \\
& \mathrm{Ni}^{2+}+4 \mathrm{H}_{2} \mathrm{O} \leftrightarrow \mathrm{Ni}(\mathrm{OH})_{4}{ }^{2-}+4 \mathrm{H}^{+} \\
& \mathrm{pK}_{4}=12,00
\end{aligned}
$$

$\mathrm{Cd}$ elementine ait adsorpsiyon ve adsorpsiyon verimi değerleri Şekil 7-8'de verilmiştir.

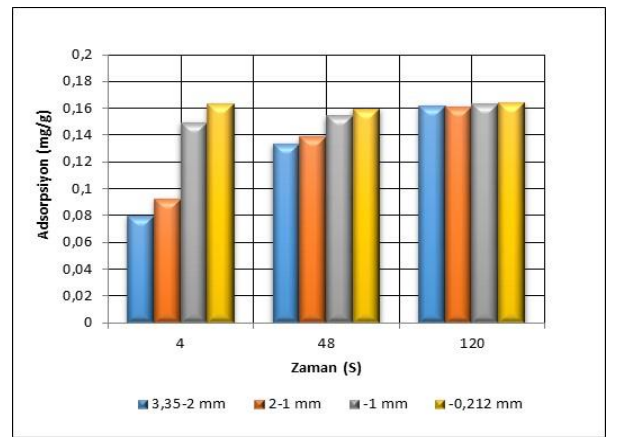

Şekil 7. Zamana bağlı olarak farklı tane sınıflarındaki zeolit üzerine $\mathrm{Cd}$ adsorpsiyonu konsantrasyon değerleri

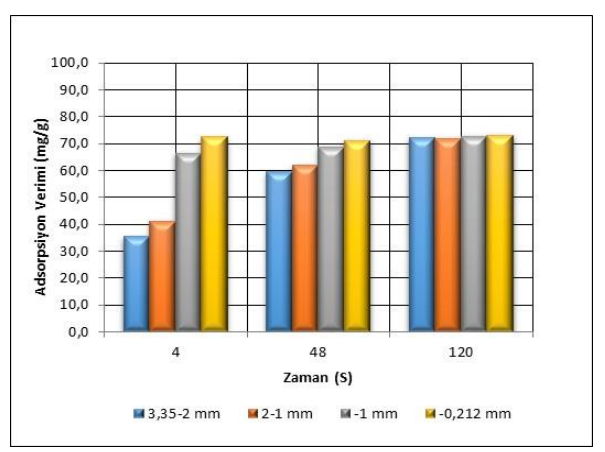

Şekil 8. Zamana bağlı olarak farklı tane sınıflarındaki zeolit üzerine Cd adsorpsiyonu verim değerleri
$\mathrm{Cd}$ iyonunun zeolit üzerine adsorpsiyonunda $11,22 \quad \mathrm{ppm} \quad \mathrm{Cd}^{2+}$ katyonu içeren çözelti kullanılmıştır. $3,35-2 \mathrm{~mm}$ ve $2-1 \mathrm{~mm}$ tane boyutlarında 4 saat sonunda adsorpsiyon miktarları sırasıyla 0,08 ve $0,09 \mathrm{mg} / \mathrm{g}$ olmuş ve buna bağlı olarak adsorpsiyon verimleri sırasıyla $\% \quad 35,5$ ve 41,1 olarak gerçekleșmiștir. Daha ince tane siniflarında $\quad(-1 \mathrm{~mm}$ ve $-0,212 \mathrm{~mm})$ adsorpsiyon miktarları 4 saat sonunda 0,15 ve $0,16 \mathrm{mg} / \mathrm{g}$ olduğu ve adsorpsiyon verimlerinin ise $\% 66,44$ ve 72,59 olduğu gözlenmiștir. 120 saat sonunda ise tüm tane sinıflarında adsorpsiyon miktarları $0,16,0,16,0,16,0,16 \mathrm{mg} / \mathrm{g}$ olduğu, adsorpsiyon verimlerinin sirasiyla $\% 72,2$, $\% 71,9, \% 72,7$ ve $\% 73,1$ olduğu tespit edilmiştir. Cd iyonu hidroliz reaksiyonları 14-19 eşitliklerinde verilmiștir [10].

$$
\begin{aligned}
& \mathrm{Cd}^{2+}+\mathrm{H}_{2} \mathrm{O} \leftrightarrow \mathrm{Cd}(\mathrm{OH}) \mathrm{H}^{+} \\
& \mathrm{pK}_{1}=10,08 \\
& \mathrm{Cd}^{2+}+2 \mathrm{H}_{2} \mathrm{O} \leftrightarrow \mathrm{Cd}(\mathrm{OH})_{2}+2 \mathrm{H}^{+} \\
& \mathrm{pK}_{2}=20,35 \\
& \mathrm{Cd}^{2+}+3 \mathrm{H}_{2} \mathrm{O} \leftrightarrow \mathrm{Cd}(\mathrm{OH})_{3}{ }^{-}+ \\
& 3 \mathrm{H}^{+} \mathrm{pK}_{3}=33,3 \\
& \mathrm{Cd}^{2+}+4 \mathrm{H}_{2} \mathrm{O} \leftrightarrow \mathrm{Cd}(\mathrm{OH})_{4}{ }^{2-}+ \\
& 4 \mathrm{H}^{+} \mathrm{pK}_{4}=47,4 \\
& 2 \mathrm{Cd}^{2+}+\mathrm{H}_{2} \mathrm{O} \leftrightarrow \mathrm{Cd}_{2} \mathrm{OH}{ }^{3+}+\mathrm{H}^{+} \\
& \mathrm{pK}_{5}=9,39 \\
& 4 \mathrm{Cd}^{2+}+\mathrm{H}_{2} \mathrm{O} \leftrightarrow \mathrm{Cd}_{4}(\mathrm{OH})_{4}{ }^{4+}+ \\
& 4 \mathrm{H}^{+} \mathrm{pK}_{6}=32,9
\end{aligned}
$$

$\mathrm{Ni}^{2+}, \mathrm{Zn}^{2+}$ ve $\mathrm{Cd}^{2+}$ katyonlarının zeolit yüzeyine adsorpsiyonlarında iyonik yarıçap, atom ağırlığı ve elektonegatiflik özellikleri ön plana çıkmaktadır. Söz konusu katyonların çözeltiden uzaklaştırılması işleminin başarısı denge sabiti değerleri ile beraber bu özelliklerde dikkate alınarak yorumlanmalıdır. Literatürde verilen $\mathrm{Kd}$, iyonik yarıçap, atom ağırlığı ve elektronegatiflik değerleri aşağıda sunulmuştur [11]. 
İyonik yarıçap: $\operatorname{Cr}(1,85 \AA) \operatorname{Cd}(0,97 \AA)>$ Zn $(0,74 \AA)>$ Ni $(0,69 \AA)$; Atomik kütle Cd $(112.41)>\mathrm{Zn}(65.38)>\mathrm{Ni}(58,71)>\mathrm{Cr}$ $(51,99)$; Elektronegatiflik Ni $(1,9)>\mathrm{Cd}$ $(1.7)>\operatorname{Cr}(1,66)>\operatorname{Zn}(1.65)[22]$ Hidroliz sabitleri $\mathrm{Cr}(3,8)>\mathrm{Ni}(4,1)>\mathrm{Zn}(9.0)>\mathrm{Cd}$ (10.1).

\section{Tartışma ve Sonuç}

Deneysel çalışmalardan elde edilen veriler incelendiğinde adsorpsiyon verimi sıralamasının $\mathrm{Cd}>\mathrm{Ni}>\mathrm{Zn}$ şeklinde olduğu görülmektedir. Ancak çözeltideki katyon derişimleri göz önüne alındığında genel adsorpsiyon başarısının $\mathrm{Ni}$ açısından oldukça yüksek olduğu sonucuna varılmaktadır. Buradan hareketle elektronegatiflik, düșük $\mathrm{pK}$ değeri ve hidrate olmuş haldeki iyonik çap değerinin söz konusu iyonların zeolit yüzeyine adsorpsiyonunda etkin özellikler içerisinde yer aldığı sonucuna varılmaktadır.

Yapılan testler sonucunda söz konusu iyonların adsorpsiyon verimlerinin göreceli kısa zaman dilimleri içerisinde daha ince taneli zeolit örnekleri için daha yüksek olduğu gözlenmiştir. Ancak, 120. saat sonunda tüm tane iriliklerinde oldukça yakın adsorpsiyon verimlerine ulașılmıștır. Kullanılan zeolit numuneleri yağmur sularından ağır metal iyonlarınının uzaklaştırılmasında etkin bir rol oynadığı gözlenmiștir.

\section{TEŞEKKÜR}

Bu çalışma'nın yürütülmesi esnasında araștırma ekibine sağladıkları her türlü imkan ve destekten ötürü; Gördes Zeolit Madencilik San. ve Tic. A.Ș. Genel Müdürü Sayın Çağatay TULUNAY'a, Ar-Ge ve Kalite Müdürü Sayın Ayșegül YÖRÜK YALÇIN'a, Fabrika Müdürü Sayın Saim URÇUN'a ve tüm çalıșma arkadaşlarına en içten teşekkürlerimizi sunarız.

\section{KAYNAKLAR}

[1] Krishna, R.R., Xie, T., Dastgheibi, S. 2014. Removal of heavy metals from urban stormwater runoff using different filter materials Journal of Environmental Chemical Engineering 2 -282292

[2] Katarzyna P., Fronczyk J., Garbulewski K., 2013. -Removal of Dissolved Metals from Road Runoff Using Zeolite PRBs Chemical Engineering Transactions vol 332,

[3] Fuhrman H.G., Mikkelsen P.S., Ledin A., 2007. Simultaneous removal of $\mathrm{As}, \mathrm{Cd}, \mathrm{Cr}, \mathrm{Cu}, \mathrm{Ni}$ and Zn from stormwater: Experimental comparison of 11 different sorbents Water Research 41 591- 602

[4] Göbel P., Dierkes C., Coldewey W.G. 2007. -Storm water runoff concentration matrix for urban areas - Journal of Contaminant Hydrology 91 26-42

[5] Erdem E., Karapinar N., Donat R., 2004. The removal of heavy metal cations by natural zeolites Journal of Colloid and Interface Science 280 309-314

[6] Ahmad M. Al-Haj-Ali* and Lana M. Marashdeh 2014. Removal of Aqueous Chromium (III) Ions Using Jordanian Natural Zeolite Tuff in Batch and Fixed Bed Modes - 2014 Jordan Journal of Earth and Environmental Sciences- Volume 6, Number 2 Pages 45- 51

[7] Demirci, S., Ustaoğlu, Z., Yılmazer G.A., Şahin F., Baç N. : 2014 Antimicrobial Properties of Zeolite-X and Zeolite-A IonExchanged with Silver, Copper, and Zinc Against a Broad Range of Microorganisms - Appl Biochem Biotechnol (2014) 
F. Turan vd. / Yüzeysel Yağmur Sularının Ağır Metal İçeriğinin Uzaklaştırılmasında Doğal Zeolitlerin Etkinliğinin Araștırılması

172:1652-1662

DOI

10.1007/s12010-013-0647-7

[8] Visa M, Popa N 2015. Adsorption of Heavy Metals Cations onto Zeolite Material from Aqueous Solution. J Membra Sci Technol 5: 133.

[9] Chen, Y., Zhang W., Yang, S., Hobiny, A., Alsaedi, A., Wang, X. 2015. Understanding the adsorption mechanism of $\mathrm{Ni}(\mathrm{II})$ on graphene oxides by batch experiments and density functional theory studies - Sci China Chem April (2016) Vol.59 No.4 - doi: 10.1007/s11426-0155549-9

[10] Baes, C. F. and MESMER, R. E. 1976. The hydrolysis of cations. John Wiley and Sons, New York London - Sydney - Toronto

[11] Shaheen S.M., Derbalah A.S., Moghanm F.S., 2012. Removal of Heavy Metals from Aqueous Solution by Zeolite in Competitive Sorption System, International Journal of Environmental Science and Development, Vol. 3, No. 4

[12] Leyva-Ramos, R.; Fuentes-Rubio, L; Maria GuerreroCoronado, R. and Mendoza-Barron, J., 2004. Adsorption of Trivalent Chromium from Aqueous Solutions onto Activated Carbon, Journal of Chemical Technology and Biotechnology, 62:64-67 